
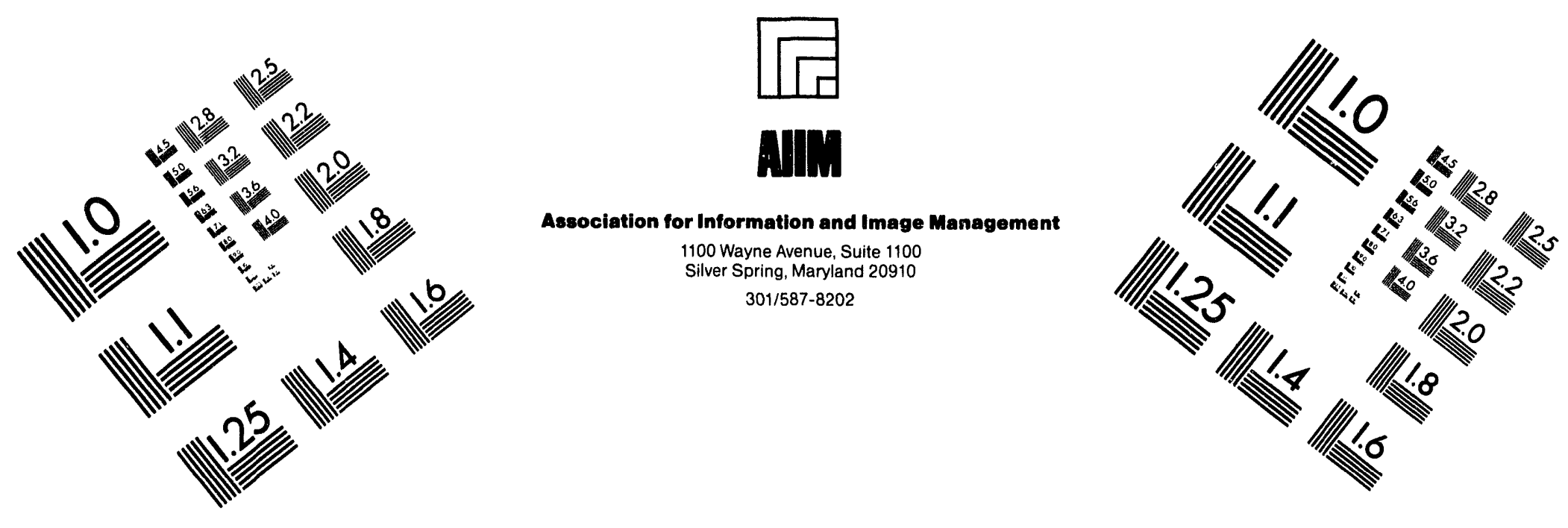

\title{
Centimeter
}

$\begin{array}{llllllllllllllll}1 & 2 & 3 & 4 & 5 & 6 & 7 & 8 & 9 & 10 & 11 & 12 & 13 & 14 & 15 & \mathrm{~mm}\end{array}$

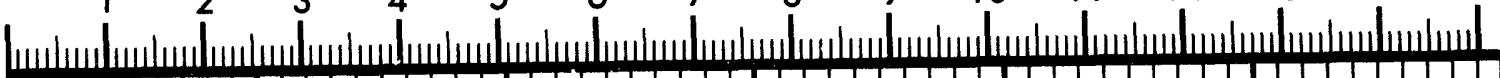
仿 Inches
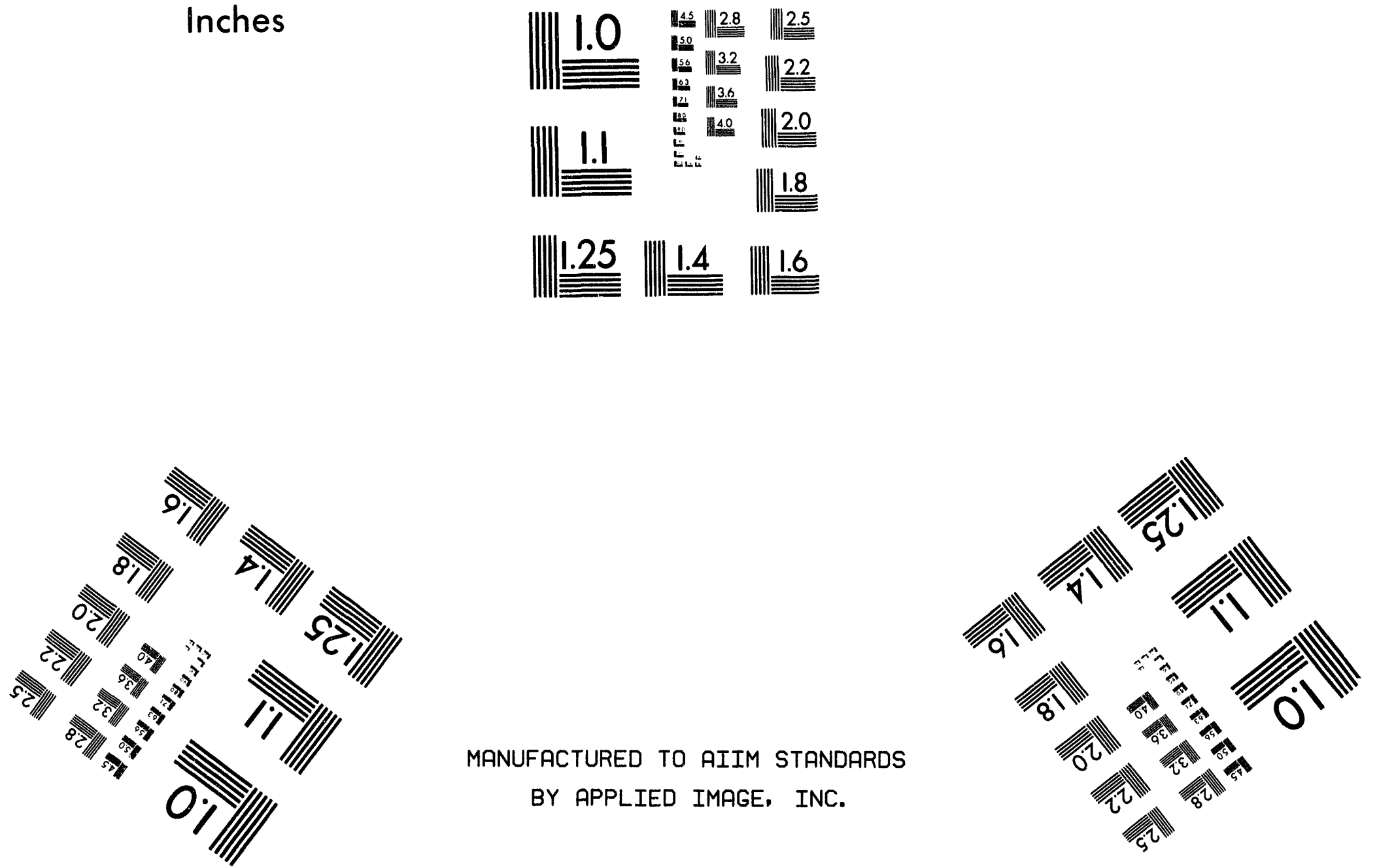

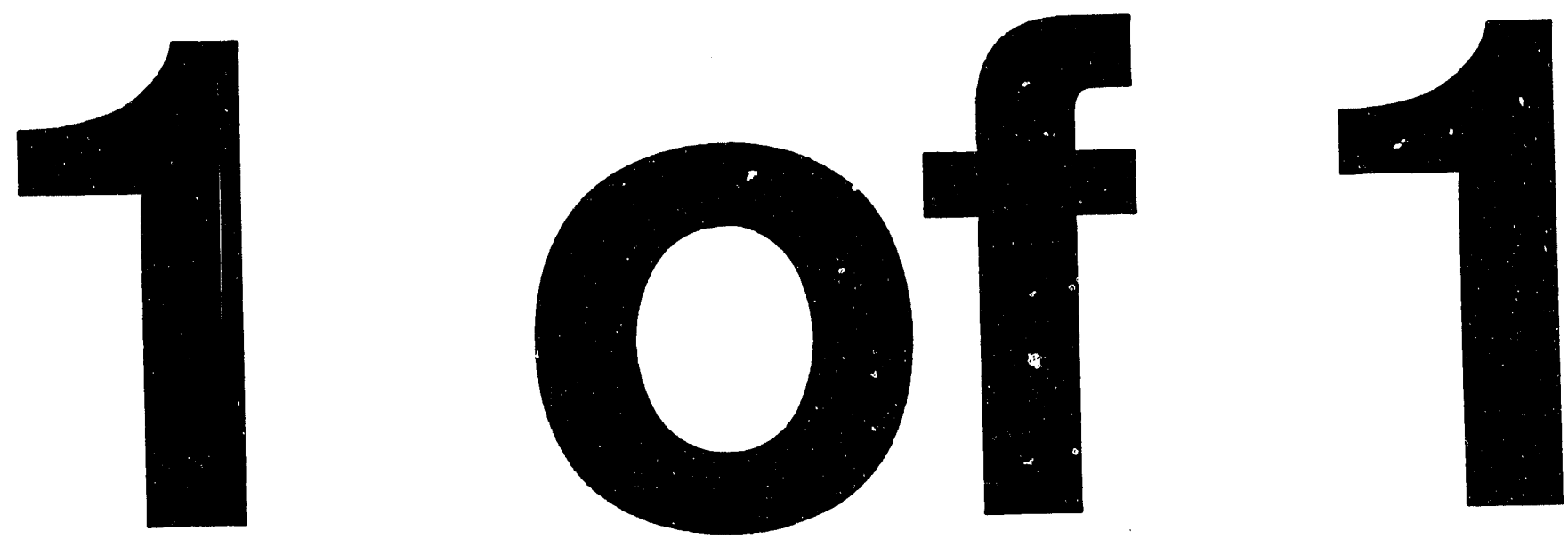


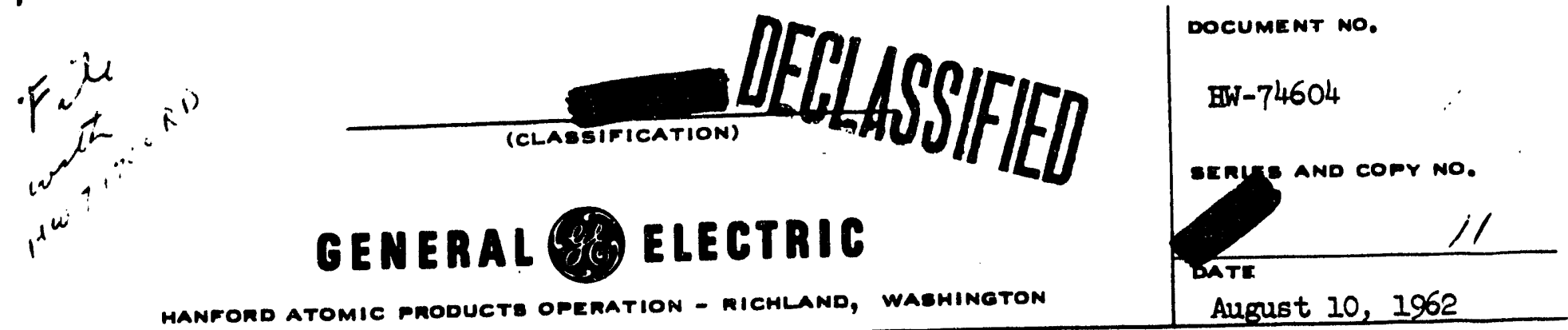

HANFOND ATOMIC PRODUCTE OPERATION - MICHLAND, WASHINGTON

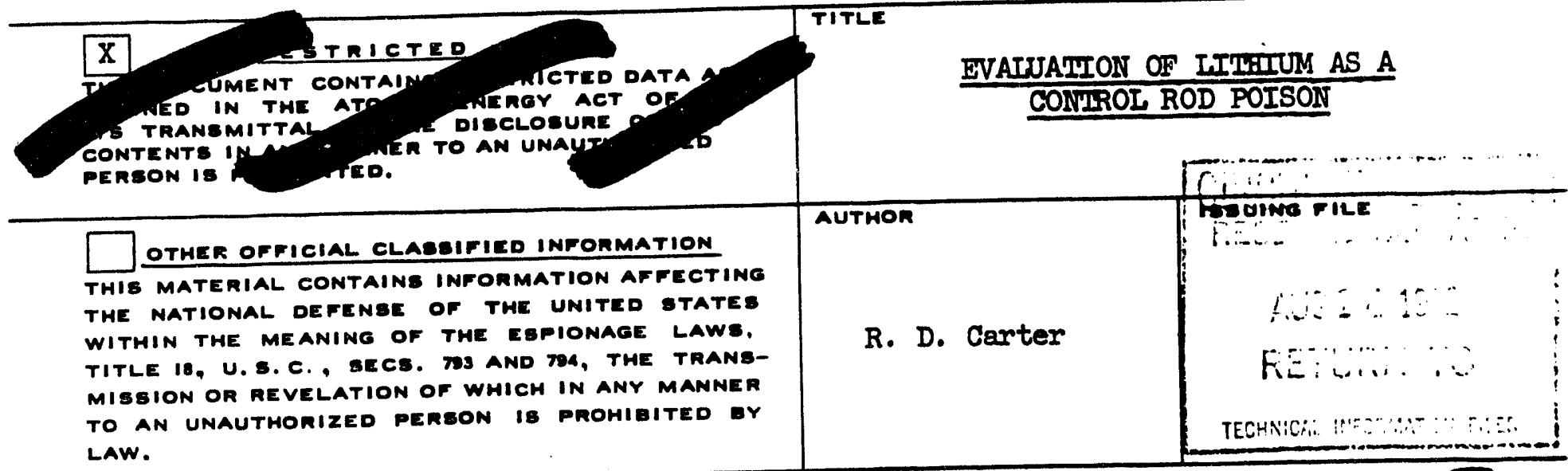

LAW.

THIS DOCM MUUST NOT DE LEFT UDED ON WHERE AN UN TO IT NOT IN UEE, IT MM

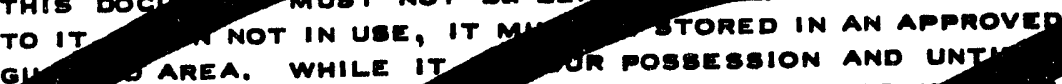
UT ROSEESEION AND UNT SIIFIED FILEB, AIS PROJECT AND OF RESIDENCE ORTAN THE THE RELATED ISSUIN
TO SIGN IN THL BPACE PROVIDED MELOW. UUR RESPONSIEILITY TO NT: ANY UNAUTHORIZED PERgO OHIEITED. IT IS NOT T?

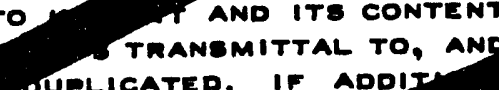
GED PERSON MAY MAVS
MOEITORY WITHIN

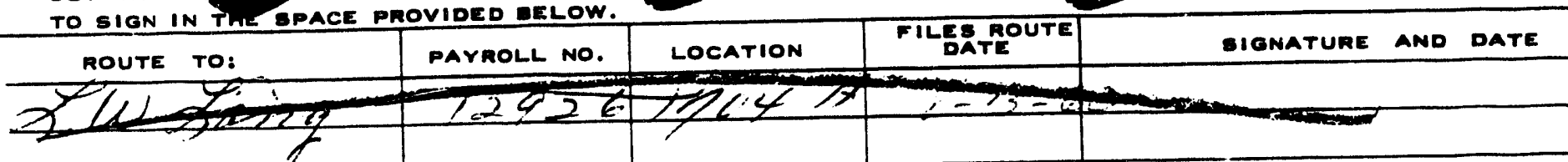




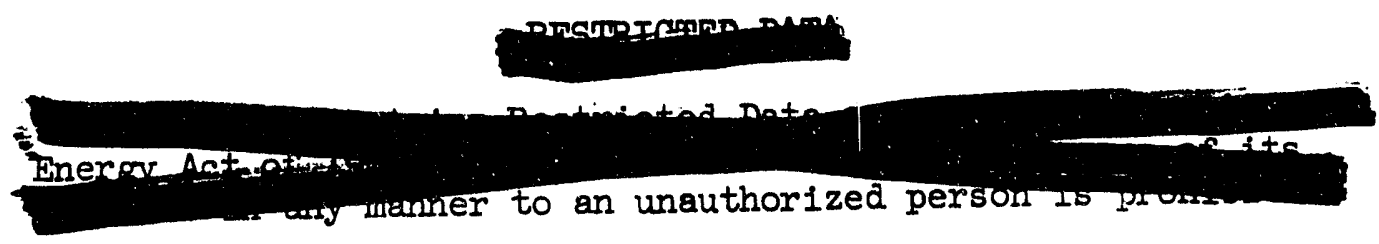

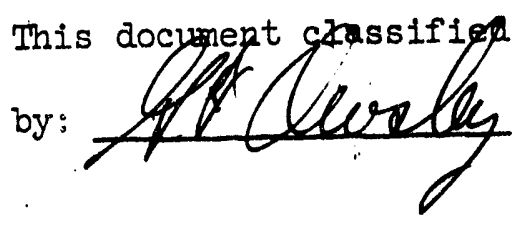

1. ER Astley

2. JH Brown

3. RD Carter

4. DL Condotta

5. GC Fullmer

6. OH Greager

7. HW Heacock

8. E. Hollister

9. DL Hovorka

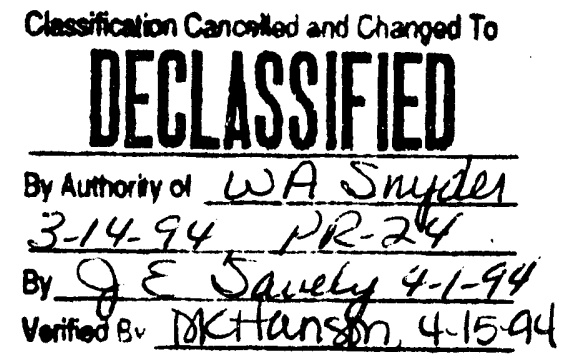

This document consists of $\frac{2}{18}$ pages. No. $/ 1$ of

Distribution

\section{EVALUATION OF IITHIUM AS A CONTROL ROD POISON}

To permit more accurate evaluation of the incentives for isotopes producing control rods a determination was performed of the tritium production which would result from conversion to lithium HCR's. A cursory examination of the gains resulting from the use of lithium shows that a significant amount of tritium could be produced in this manner totaling 1.6 percent of the present Pu-239 production on an atom equivalent basis.

Replacement of only those rods normally inserted past the near side (includes primarily the half-rods)would allow realization of 85 to 90 percent of the maximum possible gains. It would probably not be economically sound to replace rods which normally have only a short length of the tip inserted in the reactor because of their low tritium concentration. The number of deep rods to be replaced would be about five rods at each of the older reactors and seven rods at each of the $K$ reactors.

Calculation of the gains is performed in a straightforward manner. The following assumptions are made:

$c-m k$ in rods $=700$ per reactors (replaced rods)

Yearly production $=5 \times 10^{6} \mathrm{MWD}$

Pu conversion ratio (avg.) $=.835 \mathrm{~ms} / \mathrm{MWD}$

Neutrons per fission $=2.5$

of of neutrons absorbed as thermal neutrons $=90$

\% of neutrons for Pu production $=40$

Since the worth of the rods to be replaced is $700 \mathrm{c}-\mathrm{mk}$ or 0.7 percent of the neutrons available for fission the rods will absorb 0.7 percent of the thermal neutrons which 


\section{DECLLSSSFFED}

would otherwise cause fission. Therefore it can also be assumed that the rods will also absorb 0.7 percent of the thermal (but not epithermal) neutrons which would otherwise be absorbed in U-238 and various reactor structural components. The proportion of thermal neutrons absorbed in the rods compared to all neutrons absorbed in $\mathrm{U}-238$ to form Pu-239 is:

$$
(.007 \times .90) / .40=.016 .
$$

The number of grams of Pu formed per year is:

$$
5 \times 10^{6} \times .835=4.18 \times 10^{6} \mathrm{gms} \text {. }
$$

Assuming that one atom of tritium is worth one atom of Pu-239 the production of tritium in atom-equivalent grams is then:

$$
4.18 \times 10^{6} \times .016=6.69 \times 10^{4} \simeq 67,000 \text { equivalent grams (about } 840 \text { gms T). }
$$

This corresponds to a production increase of:

$$
6.7 \times 10^{4} / 4.2 \times 10^{6}=.016 \sim 1.6 \% \text {. }
$$

No attempt has been made at this point to devise elaborate calculations. For example, no consideration was made of the fact that a certain percentage of the neutrons $a b-$ sorbed in the rods will be absorbed in materials other than lithium. The results are probably subject to errors of perhaps 20 percent. However the estimated worth of the control rods was chosen such that the calculated tritium production would be conservative.

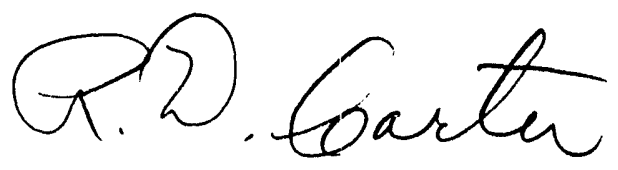

Process Physics Studies Operational Physics Sub-Section Fesearch and Englineering Section

RD Carter:gs 

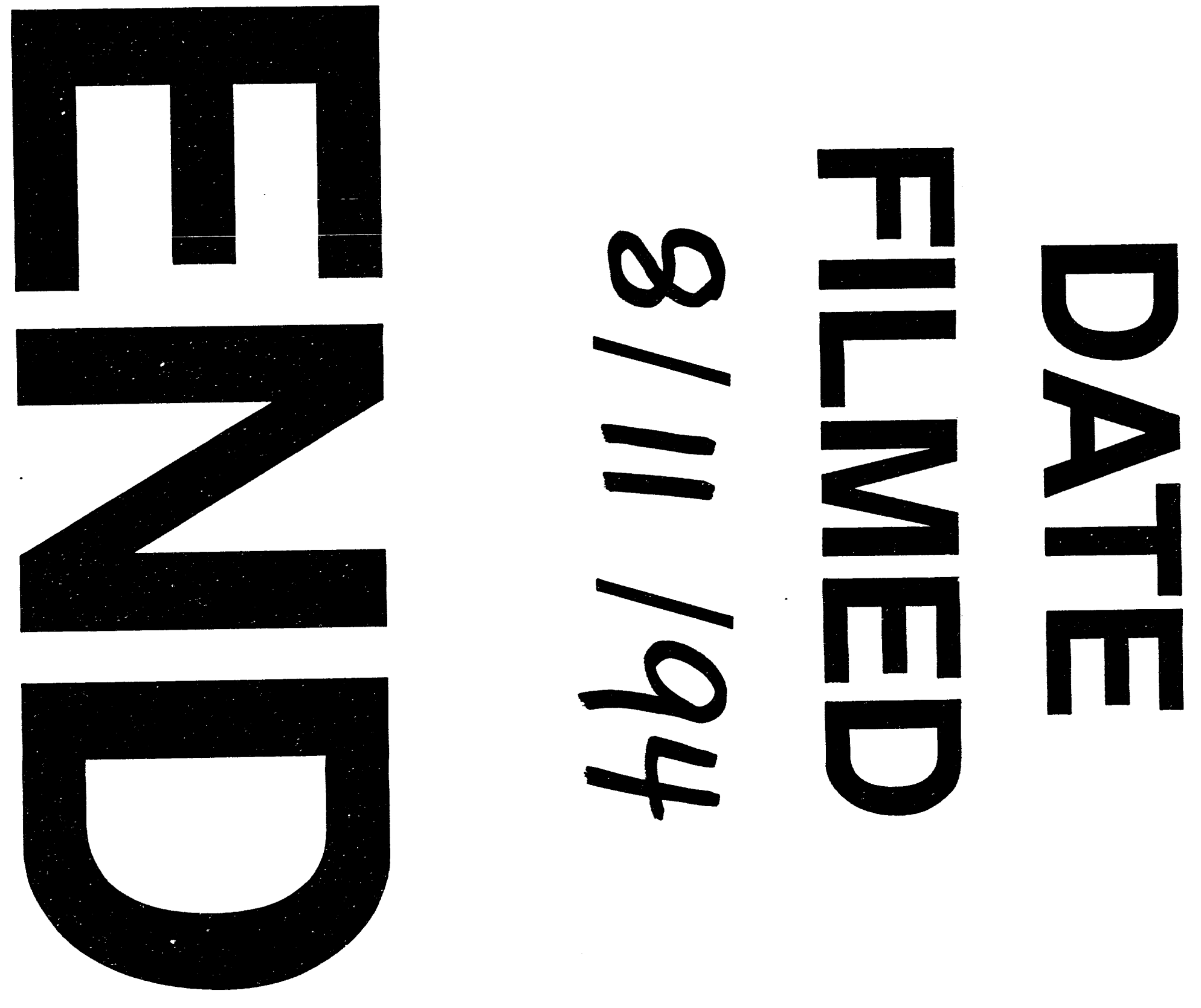
